\title{
Dilemas do desenvolvimento agrário
}

\author{
WASHINGTON NOVAES
}

$\mathrm{T}$

ALVEZ A grande questão do desenvolvimento agrário no Brasil possa ser sintetizada ao se mencionar que quase todas as políticas do setor apontam para a insustentabilidade e, ao mesmo tempo, não se vislumbram no horizonte próximo indícios de mudanças significativas - a não ser na consciência social, que começa a manifestar preocupação com seus rumos. A contradição leva a supor que poderá haver um agravamento de conflitos no curto e médio prazos.

As recentes discussões em todo o país para construção da Agenda 21 nacional mostraram com clareza o avanço da consciência social. "Agricultura sustentável” foi exatamente, entre as seis áreas temáticas de discussão, a que mais propostas recebeu: $31 \%$ do total. Se somadas a estas as propostas referentes à "gestão dos recursos naturais" (21\% do total), também muito relacionadas com a agricultura e uso do solo e outros recursos, verifica-se que mais de metade das propostas da sociedade denotavam preocupações com o que está acontecendo no campo brasileiro e no avanço da fronteira agropecuária. Mais preocupação que com cidades, redução das desigualdades sociais, infra-estrutura/energia e ciência e tecnologia, outras áreas em discussão

Onde a fronteira agropecuária avança com mais rapidez e em maior extensão, esse quadro apareceu também muito nítido. Nos estados do Centro-Oeste as propostas relacionadas com a agricultura representaram $31,5 \%$ do total, embora uma das unidades federativas da região (Distrito Federal) tenha área rural muito pequena e em duas outras (os dois Mato Grosso) haja vastas extensões (Pantanal) inapropriadas para a agricultura.

O conflito entre a preocupação, a realidade imediata e as políticas ficou da mesma forma patente nessas discussões, na medida que a quase totalidade do empresariado demonstrou absoluta recusa em discuti-lo e, mais ainda, em aceitar a internalização em suas atividades de custos ambientais e sociais - pois isso, a seu ver, agravaria o problema da competitividade, num momento de aguda disputa nos mercados interno e externo.

Vale a pena, então, retornar ao diagnóstico do setor, incluído no documento que tem servido de ponto de partida para os debates - Agenda 21 brasileira, bases para discussão. 
Apontam-se ali seis razões fundamentais que ameaçam a sustentabilidade na agricultura:

- a predominância do chamado padrão "revolução verde", intensivo em capital e em insumos químicos;

- a presença no agronegócio de graves passivos ambientais, representados principalmente pelo alto nível de erosão do solo, degradação de recursos hídricos e perda da diversidade biológica;

- a dependência científica e tecnológica do exterior, que a "revolução verde" acentua e a falta de verdadeira inovação nacional agrava;

- a predominância, no setor, do modelo exportador, pautado de fora e arcando com custos ambientais e sociais cuja prevenção/eliminação os países importadores não querem incorporar nos preços;

- conseqüência em grande parte do item anterior, uma rentabilidade que decorre em certa medida da recusa interna de incorporar esses custos e da necessidade de utilizar mais capital natural como se financeiro fosse (gerando a insustentabilidade futura);

- a estrutura fundiária fortemente concentrada e ainda tendendo para maior concentração em muitas partes.

De todos esses fatores decorrem, sem dúvida, questões complexas, e que só se resolverão a partir de um processo endógeno - não pode ser imposto de fora.

A escolha do modelo central, fundado na "revolução verde", implicou a predominância quase absoluta das culturas de ciclo curto, em geral originárias de países temperados ou frios e adaptadas às condições de solo destes, rico em nitrogênio - elemento pouco presente nos solos brasileiros. Esse e outros fatores exigem nas culturas brasileiras intensa utilização compensatória de insumos químicos, a alto custo (o Brasil é o terceiro maior consumidor mundial de agroquímicos, cerca de US\$ 2,5 bilhões/ano, nos quais pesa a importação).

Esse modelo implica também processos de desmatamento e mecanização intensivos que, por sua vez, desencadeiam outros processos problemáticos. Um deles é a compactação do solo, que, junto com os sistemas de revolvimento das áreas de cultivo (também originários dos países frios, mas em geral dispensáveis aqui), contribui para acentuar a erosão eólica, ou pelas chuvas. No Centro-Oeste brasileiro, por exemplo, o nível de perda do solo está entre 6 e $10 \mathrm{~kg}$ por quilo de grãos produzido. No país, já em 1997 documentos dos Ministérios da Agricultura e do Meio Ambiente situavam a perda nacional em um bilhão de toneladas de solo anuais. Os sistemas de plantio direto têm atenuado em algumas regiões a intensidade do problema, ainda presente na maior parte das áreas agrícolas, mas com a contrapartida de exigirem maior consumo de herbicidas. 
A esse tipo de erosão acresce-se a erosão solar, que começa a ser apontada por alguns estudiosos - fruto da alta taxa de insolação em boa parte do país, aliada à exposição do solo, que é agravada pelo revolvimento. Ela pode resultar em perda da microfauna do solo e, a prazo maior, em degradação.

O desmatamento implica ainda perda da biodiversidade brasileira, antes mesmo de bem conhecida. O Brasil detém de 20 a 22\% de todas as espécies planetárias, rico repositório de possibilidades nas áreas de medicamentos, alimentos e futuros materiais. Implica, da mesma forma, redução na capacidade dos biomas brasileiros de absorver carbono - fundamental num tempo em que mudanças climáticas se tornam a principal ameaça à sustentabilidade - e aumento nas emissões geradoras do efeito estufa, por força de alterações no uso da terra.

Vale lembrar, neste ponto, que restam pouco mais de $5 \%$ de um dos mais ricos biomas brasileiros, a Mata Atlântica, enquanto cresce a taxa anual de desmatamento na Amazônia, aproximando-se de $600 \mathrm{mil} \mathrm{km}^{2}$ a área desmatada nesse bioma. Nos Cerrados, os últimos levantamentos apontam menos de $5 \%$ do bioma efetivamente intocados, com a ocupação intensiva já próxima de $40 \%$ e alguma forma de atividade econômica no restante da área. Sem falar em mais de 800 mil $\mathrm{km}^{2}$ do Semi-Árido em processo de desertificação e cerca de $180 \mathrm{mil} \mathrm{km}^{2}$ já desertificados.

Não terminam aí as conseqüências do modelo. As altas taxas de desmatamento e erosão contribuem poderosamente para o processo de degradação das bacias hidrográficas, que, desprotegidas, se assoreiam e poluem. Para esse quadro contribuem também a emissão de efluentes na bovinocultura e na suinocultura, principalmente, mas também na avicultura (problema pouco tratado mas já com graves conseqüências em algumas regiões, com destaque para o Oeste catarinense). Outros fatores são o carreamento de agrotóxicos e, via efluentes, elementos químicos contidos em antibióticos e outros produtos.

A degradação não é a única questão nas bacias hidrográficas. A substituição de vegetação nativa por plantas de ciclo e raízes curtas também pode determinar problemas complexos, aumento do nível de evaporação e, possivelmente (não há ainda informações sistematizadas suficientes), menor nível de reposição dos lençóis freáticos e aqüíferos que abastecem mananciais.

Com certeza a irrigação intensiva tem contribuição poderosa na área, pelo forte desperdício de água, que pode chegar a $50 \%$. Um pivô central, de alto nível de consumo de água, chega a utilizar um litro por segundo por hectare irrigado. Como seu custo de implantação é pouco mais de metade do de sistemas mais eficientes no uso de água, tende a tornar-se predominante.

Há ainda outras conseqüências desse modelo. Por exemplo, a eliminação de polinizadores e predadores naturais. A última contribui para o aumento das chamadas "pragas" e intensifica o uso de agroquímicos. 
O uso intensivo de agrotóxicos e antibióticos tem gerado o surgimento de agentes super-resistentes - que exigem, para serem combatidos, ainda maior quantidade de produtos químicos, num círculo vicioso que se auto-realimenta.

Aliado ao modelo exportador, o formato de ocupação da terra e de avanço da fronteira agropecuária responde em significativa parcela pelo êxodo de população rural observado nas últimas décadas - e que tem contribuído poderosamente para os dramas da expansão urbana e da insustentabilidade progressiva das cidades brasileiras, principalmente nas áreas metropolitanas. Em 36 anos, de 1960 a 1996, a população das cidades brasileiras cresceu em mais de 90 milhões de pessoas - embora parte desse aumento seja também devido aos altos índices de fertilidade e natalidade, principalmente nas duas primeiras décadas desse período.

É certo que para esse processo migratório têm contribuído igualmente as desigualdades regionais de renda (que variam do máximo de US\$7.212 no Sudoeste para o mínimo de US\$ 2.559 no Nordeste), assim como as altas taxas de desemprego vigentes, além de outro fator poderoso, a ausência/deficiência das estruturas de atendimento à saúde, que tendem a deslocar numerosos contingentes para cidades em melhor condição.

Nas áreas urbanas, o processo contribui decisivamente para o chamado "inchaço" dos entornos, com a localização de boa parte dos contingentes migrantes em áreas de risco e inundação ou de preservação permanente. Geram eles fortíssima demanda de infra-estruturas (educação, saúde, segurança, saneamento, transportes, limpeza urbana, lazer) que não consegue ser atendida pelas finanças públicas em processo de falência.

As dimensões problemáticas tendem a se avolumar com o modelo em implantação - "corredores de transporte" principalmente voltados para a exportação agropecuária, sem considerar as reais necessidades das populações dessas áreas. É o que tem sido apontado por numerosos estudos que avaliam as conseqüências dos projetos rodoviários e hidroviários previstos para as regiões do Centro-Oeste e da Amazônia, em especial.

Tal modelo contraria ainda o conhecimento mais específico das condições de solo e clima na área amazônica, apontadas como francamente inadequadas para a agropecuária. Muitas propostas têm sido feitas para reverter tais rumos.

Pode-se começar pela reforma agrária, de modo a contemplar maior número de beneficiários e favorecer a agricultura familiar. Há, entretanto, fatores a considerar também nesse caso.

Na Amazônia, um relatório da Comissão Especial da Câmara dos Deputados que investigou a ação de empresas madeireiras apontou, já há alguns anos, que o processo de reforma agrária respondia pela maior parte do desmatamento nesse bioma. 
Mais tarde, o Ministério da Reforma Agrária baixou resolução que, por esse aspecto, proíbe novos assentamentos em áreas de floresta primária. Mesmo assim, os últimos levantamentos sobre desmatamento na Amazônia realizados entre agosto de 1999 e agosto de 2000 (quando aumentou a taxa em relação ao período anterior), nada menos de $54 \%$ do desmatamento ocorreram em propriedades de até 100 hectares - o que leva a supor que uma parcela importante tenha acontecido em áreas de assentamento, para formação de pastagens e/ou lavouras, além de geração de renda via comercialização pura e simples de madeira.

De qualquer forma, a pressão por novas áreas de assentamento tem tendido a deslocar-se para o Centro-Oeste - onde o bioma dos Cerrados já é considerado um dos hot spots, lugares mais ameaçados de perda da biodiversidade. Além disso, a legislação vigente tende a favorecer o desmatamento, por identificar a presença de vegetação nativa como caracterizadora de "terra improdutiva".

Em vários foros tem sido proposta a tese da "moratória" para os Cerrados, principalmente, ou para a Amazônia. Ela tem encontrado, entretanto, maciça resistência do empresariado da agropecuária, segundo quem a moratória implicaria perda de produtividade. Examinada mais a fundo, essa tese implica a admissão de que a produtividade se sustenta não pela atividade em si, mas pela incorporação de novas áreas desmatadas - ou seja, pela incorporação de capital tanto natural quanto financeiro. A prazo maior, significa a admissão da insustentabilidade do modelo.

Forte discussão também está presente no tema dos alimentos transgênicos, advogados por parte da comunidade científica e dos produtores rurais.

Juristas, ambientalistas e cientistas têm defendido uma postura de "cautela" diante do tema, quando nada em obediência aos termos da Convenção sobre a Diversidade Biológica, da qual o Brasil é signatário. Como não se dispõe de estudos epidemiológicos, muito menos da aferição de possíveis efeitos adversos sobre a biodiversidade (deriva genética), impor-se-ia a cautela. E esta implicaria a realização obrigatória de estudos de impacto ambiental e epidemiológicos, que exigem tempo, além de rotulagem, em caso de liberação, para respeitar o direito de escolha do consumidor. Assim, a questão continua envolta em disputas administrativas e no âmbito do Judiciário.

A tudo isso se somaria uma questão de estratégia econômica nacional. Muitos especialistas perguntam se não seria mais vantajoso o país permanecer como único grande fornecedor mundial de alimentos sem modificação genética, demandados em escala cada vez maior por muitas nações importadoras, a maior parte delas disposta a pagar sobrepreços pela garantia da não-modificação. Em tempos nos quais a preocupação com a segurança alimentar é cada vez maior (por causa da doença da "vaca louca", da aftosa, da contaminação por dioxinas, do surgimento de novos vírus e bactérias super-resistentes) - impondo certificação de origem para quase tudo -, trata-se de argumento poderoso. 
Altamente preocupante, em todo esse quadro, é a reduzida discussão, nos Estados, do tema Ciência e Tecnologia no âmbito da Agenda 21 brasileira. As propostas nessa área significaram pouco mais de $10 \%$ do total. E em sua imensa maioria, eram pontuais.

Vários relatórios têm apontado a necessidade imperiosa e urgente de ampliar a capacidade inovadora da ciência e da tecnologia nacionais, para aumentar a competitividade econômica do país em termos globais, e para construir formatos internos de desenvolvimento econômico sustentável.

Todo esse quadro, é preciso repetir, sugere a necessidade de soluções endógenas, negociadas entre os vários atores que participam do processo e a sociedade como um todo. Não fariam sentido, nem seriam eficazes, soluções e/ou modelos impostos de fora ou de cima. Sugere também caminhos que levem a uma sustentabilidade progressiva, como propõe o diagnóstico do setor para a Agenda 21.

O ponto de partida terá de ser, evidentemente, a explicitação dos conflitos, plena e sem reserva - tarefa de que se têm esquivado muitos setores, principalmente nas áreas governamentais e empresariais, dados os problemas implícitos nessa postura, a começar pelo reconhecimento da existência de custos a incorporar. Se, entretanto, a explicitação não ocorrer, obviamente se tornará muito problemático qualquer encaminhamento de soluções. Tenderá a permanecer o status quo, com agravamento dos conflitos e eventuais rupturas.

Para que seja possível avançar, será preciso começar por definições estratégicas que explicitem qual a inserção internacional desejada pelo país e suas repercussões na área do desenvolvimento agrário. Essas definições envolveriam negociações em vários foros, entre eles os da Organização Mundial de Comércio, Mercosul, Alca, FAO - para citar apenas alguns - incluindo questões como subsídios, legislação de patentes, normas de controle sanitário, mecanismos de formação de preços, absorção de custos ambientais (inclusive perda de biodiversidade) e energéticos etc.

Sem tais definições, será extremamente problemático avançar em questões como a dos custos ambientais, por exemplo. Mantidos os atuais mecanismos de formação de preços de produtos primários - que envolvem domínio de mercados, concessão de subsídios, entre outros fatores -, como se fará, por exemplo, para caminhar em direção a internalizar, nos preços dos produtos locais, os custos ambientais e energéticos? Se estes forem incorporados - controle de erosão, irrigação por métodos adequados, tratamento de efluentes, moratória no desmatamento - haverá um sobrepreço nos produtos, que terá de ser repassado aos consumidores externos. Mas isso acontece num momento em que a tendência dos mercados externos é de baixa cotação para produtos primários, e não de alta. Os mecanismos de subsídios dos grandes importadores a sua produção própria são parte relevante do processo e precisariam ser revistos - mas a recusa é formal. 
As estratégias de mercado são decisivas e precisam ser revistas - aí incluída a discussão sobre transgênicos, a tendência dos importadores de só comprar produtos sem beneficiamento para beneficiar-se da agregação de valor (via industrialização e comercialização) em seus territórios. Não há como ignorar o processo de transferência para cá de atividades com altos custos ambientais, para que estes ocorram aqui e não influam na formação do preço de produtos exportados para os países que realocam essas atividades.

Definidos os formatos de inserção internacional, outras definições estratégicas internas teriam de ocorrer - a começar pelas propostas mais abrangentes para a Amazônia e os Cerrados.

Com relação ao bioma amazônico, os especialistas na prática têm convergido quanto ao essencial, principalmente quanto à prioridade maior - a conservação da floresta nativa -, até mesmo porque - repetindo - a ciência continua a dizer que a grande maioria dos solos e climas não se adequa à agricultura e à pecuária tradicionais; não faria sentido, portanto, remover a floresta para implantá-las, nem mesmo em nome de um modelo exportador, igualmente questionado.

Isso exige, inicialmente, repensar o modelo de corredores de exportação já em implantação. Exige, da mesma forma, reavaliar o sistema exportador de eletrointensivos, que, pela alta demanda de energia elétrica, supõe a implantação de novas megabarragens e inundação de extensas áreas. É um processo no qual se absorvem internamente altos custos ambientais e energéticos (no alumínio, quase $50 \%$ dos custos de produção têm de ser debitados à energia) e, ainda, a prosseguir o atual quadro, com altos subsídios no custo da energia.

Os mesmos especialistas são também unânimes em que se comece pela implantação, em cada estado, dos zoneamentos ecológico-econômicos, capazes de definir o que se deve e não se deve fazer em cada subsistema estadual - lembrando que são extremamente diversificados e excluem generalizações.

A conservação da floresta impõe a implantação de um programa nacional e a certificação obrigatória da extração de madeira (hoje, dizem relatórios oficiais, cerca de $80 \%$ da madeira extraída são ilegais); aconselha também o cumprimento do compromisso presidencial de transformar pelo menos $10 \%$ da floresta em áreas de conservação, assim como impõe que se leve à prática, com urgência, o programa de corredores ecológicos, capazes de, por sua extensão, permitir a conservação das complexas cadeias da biodiversidade.

A conservação, sem dúvida, precisará estar em ampla relação com os programas de implantação de um sistema de pesquisa e desenvolvimento voltado para a diversidade biológica, já iniciado.

Recomendam, por outro ângulo, um reforço considerável para os sistemas de monitoramento e fiscalização tanto de atividades madeireiras como de pre- 
venção de queimadas. O Brasil tem um privilégio - uma taxa de 3,2 ha de floresta por habitante (segundo o Comitteen on Forestry, da FAO), contra uma taxa média mundial de 0,6 ha. Não pode desperdiçá-lo, nem permitir que a remoção da floresta afete outra situação privilegiada - cerca de $8 \%$ do fluxo superficial da área de água no planeta.

Seria preciso, para atingir esses objetivos, reconsiderar prioridades nos orçamentos públicos, já que o setor ambiental tanto nos orçamentos federais quanto nos estaduais são ínfimos, quer para custeio, quer, principalmente, para investimentos.

Se um desenvolvimento sustentável pressupõe todos esses pontos na Amazônia, implica também que não se faça dos Cerrados o escoadouro dos problemas, à custa da perda de sua diversidade biológica (um terço do total brasileiro) ou de seus serviços naturais, principalmente com a erosão do solo e comprometimento das suas bacias hidrográficas, que dão origem ou alimentam as três grandes bacias brasileiras (amazônica, Paraná-Paraguai e São Francisco), além de serem vitais para os grandes aqüíferos subterrâneos.

É preciso, portanto, discutir a tese da moratória para os Cerrados, juntamente com uma readequação dos sistemas exploratórios, aí incluídas a reforma agrária e a construção de um sistema efetivo e abrangente de segurança alimentar - que é uma exigência dos mercados interno e externo - baseado na rastreabilidade de todos os produtos. Isso favorecerá, certamente, uma evolução para sistemas de agricultura/fruticultura orgânica, provavelmente mais adaptáveis à agricultura familiar, que muitos especialistas propõem incentivar. Favorecerá também a evolução dos sistemas de plantio direto e criação do "boi verde", além de a exigência de tratamento prévio de efluentes da bovinocultura, suinocultura e avicultura, para evitar degradação do solo e das bacias hidrográficas.

A irrigação terá de incorporar custos de implantação de sistemas mais eficientes, menos desperdiçadores, e precisará evoluir nos estudos sobre a relação entre o uso da água, culturas irrigadas, níveis de evaporação, reposição de mananciais. A nova legislação sobre recursos hídricos, já em vigor, com a implantação de comitês de gerenciamento de bacias (com a participação da sociedade, além de governos e usuários), poderá favorecer o processo. Será preciso, entretanto, evitar que prossiga a tendência de as Assembléias Legislativas estaduais votarem leis que isentem do pagamento pelo uso de água os chamados setores produtivos, principalmente a agricultura, maior consumidora (70\% do total).

Seria indispensável, como base de tudo, repensar as relações entre o rural e o urbano, na linha que tem sido proposta por pensadores como Ignacy Sachs, José Ely da Veiga, Ricardo Abramovay: deixar de entender o rural apenas como agricultura e esta somente como produção de grãos. As possibilidades são muitas, desde a agregação de valor em matérias-primas à exploração sustentável de 
biomassa, passando por atividades como fruticultura, floricultura, realocação de atividades assistenciais - num processo que modifique profundamente as atuais relações entre o urbano e o rural, com este tornando-se inclusive gerador de ocupações para a mão-de-obra ociosa nas cidades.

Impõe-se ainda uma reformulação do sistema de ensino rural, que o adeqüe às novas necessidades e aos novos tempos - sem recorrer ao controvertido, discutível, caminho de desativar escolas rurais e obrigar a população do campo a educar-se na cidade. Não só o sistema urbano é incapaz de prepará-las paras o mercado de trabalho rural, como contraria o desejo da própria clientela das escolas, que, segundo várias pesquisas, não quer se transferir para as cidades (por saber que não encontrará lugar no mercado de trabalho e enfrentará pior qualidade ambiental).

Nas regiões que correspondem aos biomas da Mata Atlântica e da Caatinga permanece válida grande parte das questões até aqui levantadas, a começar pelo modelo exportador e suas implicações, passando pelos mesmos problemas com relação a solo, recursos hídricos, perda de biodiversidade. Da mesma forma, as questões referentes a reforma agrária e agricultura familiar, relações entre urbano e rural, diversificação de atividades no campo, especificidades do ensino.

Para o domínio da Mata Atlântica, o diagnóstico mencionado sugere ainda a adoção de "pactos territoriais" que, ao envolverem em negociações governos, empresariado e sociedade (inclusive consumidores), evitem a formação de “arquipélagos" tendentes a ações isoladas que não assegurem a implantação de uma estratégia, ou não sejam abrangentes.

O modelo básico poderia derivar dos numerosos comitês de gerenciamento de bacias hidrográficas já existentes. Pressupõe o desenvolvimento e a adoção de tecnologias "limpas", assim como a substituição das monoculturas por sistemas rotacionais. Tudo dependerá, entretanto, da formulação e implementação de políticas públicas integradoras.

No campo específico da diversidade biológica - que abre a possibilidade de muitas iniciativas de exploração sustentável - parece indispensável a implantação de corredores ecológicos nos mesmos moldes previstos para a Amazônia.

Já no Semi-Árido, o caminho básico seria o dos "métodos de convivência" com as condições climáticas específicas da região, já testados pela Embrapa, por organizações como a "Caatinga" e pelo engenheiro José Artur Padilha, com seu sistema de microbarragens encadeadas para retenção de água e refertilização de patamares. Ou seja, trata-se não de implantar megaprojetos - que a experiência tem mostrado serem de escassa eficiência - mas de um conjunto de operações que podem melhorar a eficiência no aproveitamento dos recursos disponíveis. 
Como tem demonstrado o professor Aldo Rebouças, da USP, o problema maior na região não é a escassez de água (só um estado - Pernambuco - tem situação crítica quanto à disponibilidade), mas de gestão competente.

A base para um desenvolvimento agrário sustentável estaria, assim, em um tripé que inclui a geração e disseminação de tecnologias apropriadas, a capacitação dos agricultores e de todos os membros da família e a organização desses agricultores.

Por esses rumos, parece claro que a questão do desenvolvimento rural no país passa por numerosas questões, desde as estratégias mais amplas, globais mesmo, até sua inter-relação com quase todas as políticas públicas e problemas internos.

Para equacioná-las e encaminhar soluções adequadas, a sociedade terá de ser capaz de explicitar os conflitos e articular - com a participação de governos, empresários e sociedade - políticas competentes, que coloquem no centro e no início de todas as formulações as questões ambientais, além de sua articulação com todas as áreas.

Se não for assim, continuaremos a enfrentar falsos problemas ou a gerar propostas de solução frágeis, inconsistentes, efêmeras.

Washington Novaes, jornalista, é consultor ambiental e ex-secretário estadual de Meio Ambiente, Ciências e Tecnologia de Brasília (DF). 